\title{
AS TRANSFORMAÇÕES NO USO E COBERTURA DA TERRA E SUAS CONSEQUÊNCIAS NAS INUNDAÇÕES NA BACIA HIDROGRÁFICA DO RIO MATARUNA EM ARARUAMA/RJ
}

\author{
Maria Catarina da Silva Azevedo ${ }^{(a)}$, Vinicius de Amorim Silva ${ }^{(b)}$ \\ (a) Mestranda do Programa de Pós Graduação em Geografia/Instituto de Ciências da Sociedade e Desenvolvimento \\ Regional, Universidade Federal Fluminense, catarinauff@gmail.com \\ (b) Professor do Programa de Pós Graduação em Geografia/Instituto de Ciências da Sociedade e Desenvolvimento \\ Regional, Universidade Federal Fluminense e do Centro de Formação em Tecno-Ciências e Inovação-CF-TI/Instituto \\ de Humanidades Artes Ciências- IHAC- Campus Jorge Amado -CJA, Universidade Federal do Sul da Bahia- UFSB, \\ vinymorim@gmail.com.
}

\section{EIXO: BACIAS HIDROGRÁFICAS E RECURSOS HÍDRICOS: ANÁLISE, PLANEJAMENTO E GESTÃO}

\section{Resumo}

O objetivo principal deste trabalho consiste em identificar na bacia hidrográfica do rio Mataruna, por meio das imagens de satélite, as mudanças no uso e cobertura da terra e sua influência em eventos de inundações. Para analisar a dinâmica no uso e cobertura da terra na bacia hidrográfica do rio Mataruna, foram adquiridas as imagens do satélite Ikonos (2002 e 2016) e interpretadas em ambiente SIG (Sistema de Informações Geográficas) com uso do software ArcGis 10.3. As classes de uso e cobertura utilizadas foram: área urbana, pastagem, vegetação secundária e florestas. Foram realizadas pesquisas bibliográficas e trabalhos de campo. A bibliografia contou com o documento - Plano Diretor e de Saneamento Básico de Araruama, além de publicações sobre a história local. Os resultados permitiram identificar as transformações na paisagem decorrentes do uso e cobertura da terra e sua influencia nas inundações.

Palavras chave: bacia hidrográfica; Inundações, Uso e cobertura da terra.

\section{Introdução}

As inundações estão os principais desastres naturais que atingem milhares de pessoas anualmente. Entre as principais causas das inundações estão às transformações no uso e cobertura da terra, sobretudo o avanço da urbanização. Segundo Tucci (2010), nas áreas urbanas, a intensificação dos processos ocorre devido à diminuição da capacidade de infiltração e o aumento da velocidade do fluxo superficial causados pela impermeabilização do solo.

Com o crescimento das cidades, áreas de inundação natural dos rios frequentemente são ocupadas de forma desordenada, o que contribui para as inundações desde as maiores metrópoles do país até pequenas cidades do interior. 


\section{OS DESAFIOS DA GEOGRAFIA FÍSICA NA FRONTEIRA DO CONHECIMENTO \\ Instituto de Geociências - Unicamp \\ Campinas - SP \\ 28 de Junho à 02 de Julho de 2017}

A análise das inundações urbanas e suas consequências são decorrentes de três perspectivas fundamentais: o âmbito climático, para analisar o regime hidrológico; o topográfico, para identificar o perfil transversal dos canais e o antrópico, onde as modificações impostas ao meio devem ser observadas (Vieira, 2005). A interação entre estes diferentes elementos confere às inundações uma grande complexidade devido à atuação de diferentes fatores que podem atuar de forma isolada ou integrada.

\subsection{Caracterização da área de estudo}

O presente trabalho tem como área de estudo a bacia hidrográfica do rio Mataruna, localizada integralmente em Araruama/RJ. Com uma área de 49,5 km², representa menos de $8 \%$ do território do município $\left(638 \mathrm{~km}^{2}\right)$, mas concentra cerca de $29 \%$ de sua população, formada por mais de 40 mil habitantes (IBGE, 2010). Esta área concentrou um substancial crescimento populacional nas últimas décadas e que contribuiu para a expansão urbana desordenada. Estas ocupações se desenvolveram, principalmente, em terrenos de baixa declividade (inferior a $2 \%$ ), naturalmente sujeitos às inundações durante as chuvas de maior intensidade e concentração, que provocam prejuízos aos habitantes das áreas mais críticas Figura 1.

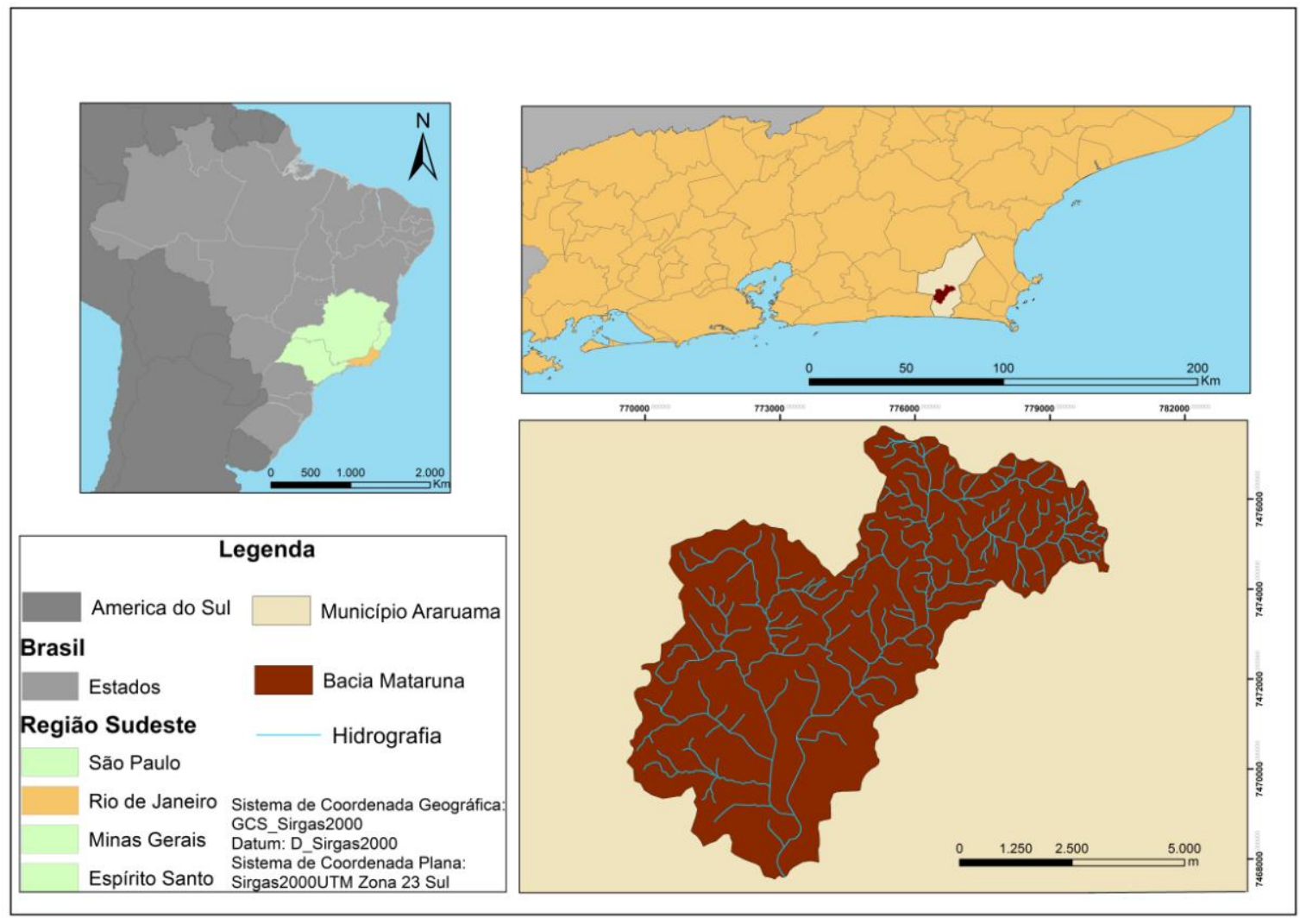

Fig. 1- Localização da Bacia do Rio Mataruna-Araruama/RJ 
Elaboração da autora.

De acordo com os aspectos geomorfológicos, a bacia hidrográfica do rio Mataruna está inserida na Unidade Geomorfológica Baixadas da Região dos Lagos. As partes mais elevadas são representadas por colinas baixas de superfície aplainada e morros isolados e as baixadas são formadas pelas planícies aluviais, compostas por material areno-argiloso que forma planícies de inundação, terraços fluviais e leques colúvio-aluvionares (SILVA, 2007). Os aspectos climáticos destacam-se devido à baixa pluviosidade, em torno de 900 milímetros anuais. Segundo Barbieri (1975), esta área do litoral fluminense caracteriza-se como uma "mancha seca" no úmido litoral do Estado do Rio de Janeiro. Embora as chuvas não sejam frequentes, ocorrem com grande intensidade e concentração, com graves consequências para a população.

O presente trabalho tem relevância na compreensão da dinâmica do uso e cobertura da terra ocorrida na bacia do rio Mataruna, nos anos de 2002 e 2016, e mostra a necessidade de ações planejadas a partir da visão integradora da bacia hidrográfica como unidade territorial. Portanto, o objetivo principal deste trabalho consiste em identificar, através das imagens de satélite (Ikonos 2002 e 2016), as mudanças ocorridas no período e possíveis relações com as inundações.

\section{Metodologia}

Para analisar as mudanças no uso e cobertura da terra na bacia hidrográfica do rio Mataruna, foram realizadas pesquisas bibliográficas e o uso de técnicas de sensoriamento remoto, como a composição de imagens orbitais e tratamento das mesmas. A bibliografia contou com o documento - Plano Diretor e de Saneamento Básico de Araruama, publicações sobre a história local, além de notícias sobre inundações no período. Para a elaboração da base cartográfica, a primeira etapa consistiu na aquisição da carta topográfica na escala 1:50.000 (IBGE/1978), que serviu para a delimitação da área e atividades de campo. Devido a necessidade de atualização dos dados, foi elaborada uma nova base cartográfica a partir do Modelo Digital de Elevação (MDE), extraído do INPE, na escala 1:25 000. Nesta base foram definidos os limites da bacia, rede de drenagem e curvas de nível. Para identificar as áreas de expansão urbana, foram adquiridas as imagens do satélite Ikonos (2002 e 2016) e interpretadas em ambiente SIG (Sistema de Informações Geográficas) com uso do software ArcGis 10.3. Esta etapa foi realizada no laboratório de Cartografia do Programa de Pós-Graduação em Geografia da Universidade Federal Fluminense com a finalidade de identificar as transformações na paisagem decorrentes do uso e cobertura da terra. 


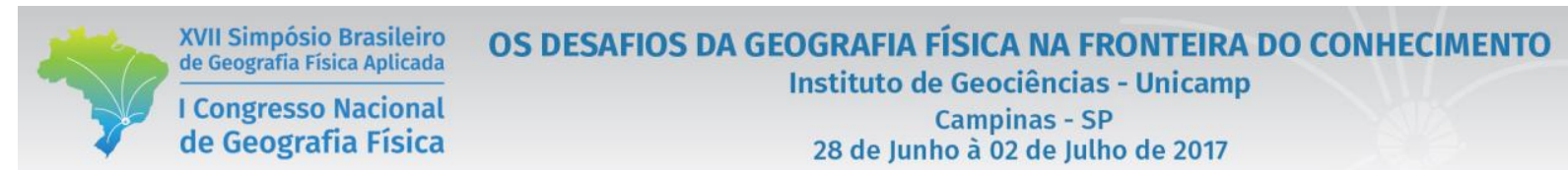

A classificação do uso e cobertura da terra dos anos de 2002 e 2016 foi elaborada de acordo com as seguintes classes: área urbana, pastagem, vegetação secundária e florestas (Tabela 1). A partir destas classes, foram consideradas áreas permeáveis as seguintes classes: pastagens, vegetação secundária e florestas. As áreas urbanas foram consideradas como áreas de permeabilidade reduzida em razão das construções e pavimentação de ruas.

Tabela I - Bacia hidrográfica do rio Mataruna: Classificação do Uso e Cobertura da Terra -2002 e 2016.

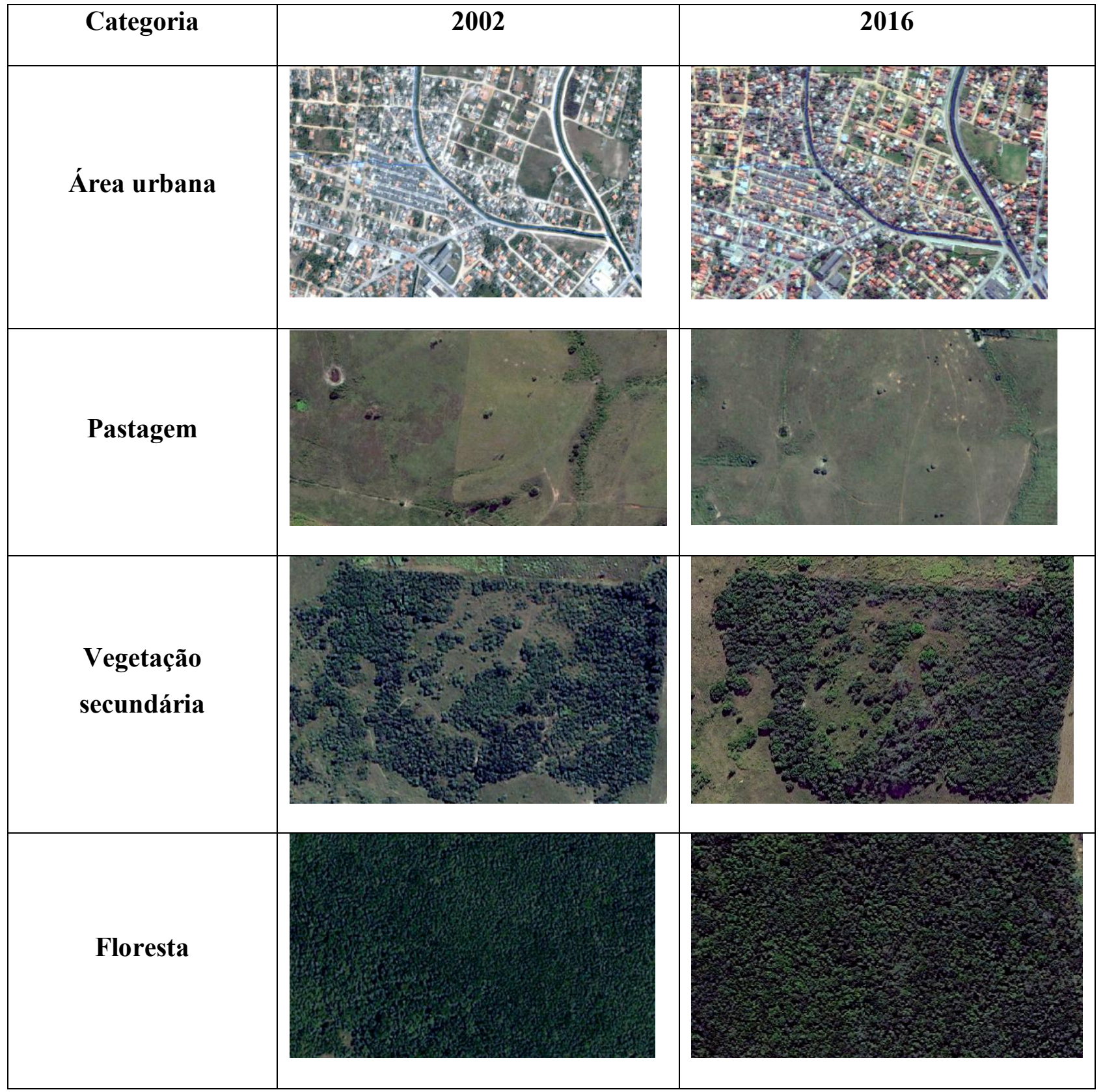

Fonte: Imagens Ikonos em 2002 e 2016. Elaboração da autora. 
As inundações foram analisadas em relação ao período de ocorrência, intensidade $(\mathrm{mm})$ e danos à população. Os dados foram obtidos através de registros da Defesa Civil Municipal, Banco de Dados do CEMADEN, reportagens de jornais e sites de notícias locais e entrevistas com moradores e comerciantes.

A partir da definição das classes, foram elaborados os mapas de Uso e Cobertura da Terra para os anos e 2002 e 2016 com o objetivo de identificar as mudanças ocorridas no período em relação à permeabilidade do solo e sua influencia nas inundações.

\section{Resultados e discussões}

A partir da interpretação das imagens ikonos em ambiente SIG, foram elaborados os mapas de classificação de uso e cobertura da terra para os anos de 2002 e 2016, que possibilitaram a visualização das transformações ocorridas no período (Figura 2).

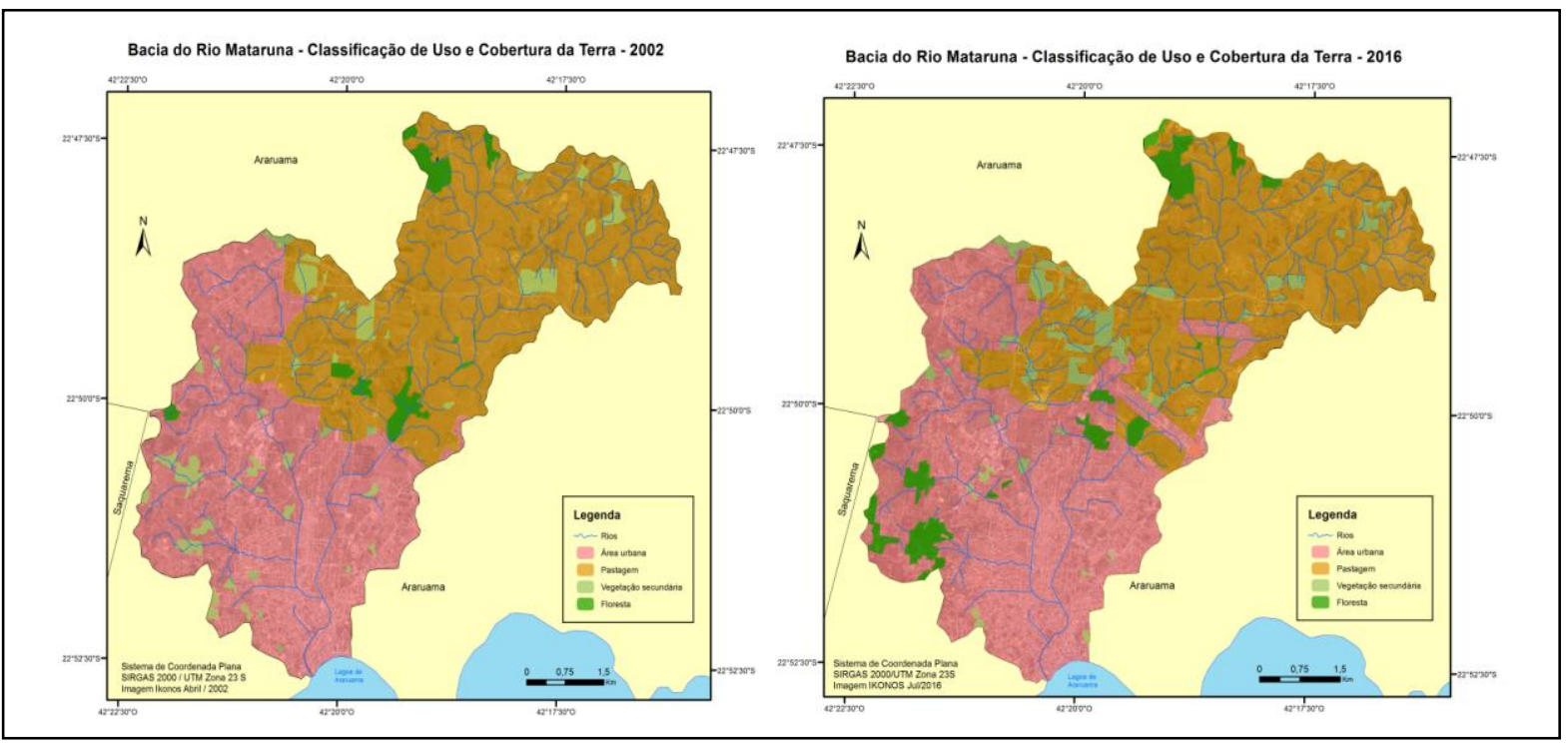

Figura 2 - Classificação de uso e cobertura da terra para a bacia do rio Mataruna/ 2002 e 2010.

Elaboração da autora.

A análise das imagens mostrou que as áreas urbanas apresentaram um crescimento de 3,6\% entre 2002 e 2016 e o maior adensamento das áreas já ocupadas. A expansão urbana ocorreu principalmente com a criação de condomínios residenciais em áreas de antigas propriedades rurais. Estes empreendimentos são projetados para a venda dos terrenos e posterior construção das residências pelos novos proprietários. Diante do avanço das áreas urbanas e maior adensamento das áreas já urbanizadas, constatou-se que houve redução da permeabilidade no período. A diminuição da permeabilidade pode provocar alterações na dinâmica fluvial, com o aumento do fluxo superficial e contribuir para as inundações. 
Em relação às pastagens, houve a redução de suas áreas em 2,6\%, conforme os dados da tabela 2. Nas áreas em que houve redução, verificou-se o aumento das áreas de vegetação secundária e a expansão das áreas urbanas.

Tabela II- Classes de uso e cobertura da terra em área e porcentagem / 2002 e 2016.

\begin{tabular}{|c|c|c|c|c|}
\hline \multirow{2}{*}{ Classe } & \multicolumn{2}{|c|}{2002} & \multicolumn{2}{c|}{2016} \\
\cline { 2 - 5 } & $\mathbf{K m}^{\mathbf{2}}$ & $\%$ & $\mathbf{K m}^{2}$ & $\%$ \\
\hline Área urbana & 22,7 & 45,9 & 24,5 & 49,5 \\
\hline Pastagem & 23,1 & 46,6 & 20,5 & 41,4 \\
\hline $\begin{array}{c}\text { Vegetação } \\
\text { secundária }\end{array}$ & 2,5 & 5,0 & 2,2 & 4,4 \\
\hline Floresta & 1,2 & 2,4 & 2,3 & 4,6 \\
\hline
\end{tabular}

Fonte: Dados obtidos através da interpretação das imagens orbitais Ikonos 2002 e 2016

As áreas de vegetação secundária apresentaram redução no total em $0,6 \%$. Estas formações vegetais foram substancialmente reduzidas na área urbana em relação aos dados de 2002. No entanto, apresentaram crescimento em meio às pastagens, o que mostra uma pequena recuperação da vegetação no médio curso da bacia do rio Mataruna.

As áreas ocupadas por florestas apresentaram a maior variação percentual. As causas das alterações tanto nos percentuais quanto na distribuição espacial das florestas e vegetação secundária indicam relação inerente aos tipos de uso e ocupação da terra. A pecuária é a principal atividade e apresentou estagnação no período analisado. Segundo dados da Pesquisa da Pecuária Municipal (IBGE), em 2000 o total de animais era de 42.200 bovinos. Para o ano de 2015, a pesquisa registrou 42.739 animais. A pequena variação dos números de animais e a maior conscientização dos produtores indicam estar favorecendo a recuperação da cobertura vegetal. Os prejuízos causados pela escassez de água mostram a necessidade de conservação do solo e recursos hídricos. Em relação à permeabilidade, a bacia do rio Mataruna apresentou uma redução de 3,6\% devido ao crescimento das áreas urbanas.

\subsection{Inundações}


XVII Simpósio Brasileiro

de Geografia Fisica Aplicada

I Congresso Nacional

de Geografia Física
OS DESAFIOS DA GEOGRAFIA FÍSICA NA FRONTEIRA DO CONHECIMENTO

Instituto de Geociências - Unicamp

Campinas - SP

28 de Junho à 02 de Julho de 2017

A urbanização diminui a permeabilidade do solo e aumenta o fluxo superficial, fator determinante nas inundações urbanas. Varias medidas são adotadas para reduzir os efeitos destes desastres naturais que atingem desde as grandes metrópoles até pequenas cidades (GALVÃO, 2014).

Para aumentar o fluxo das águas pluviais que chegam aos rios e córregos, várias medidas são adotadas. As mais comuns são chamadas medidas estruturais, formadas pelas obras de engenharia como retificações e canalização do rio, que buscam aumentar a velocidade do fluxo e reduzir os efeitos das inundações (CANHOLI, 2005). Grande parte das cidades concentram obras estruturais baseadas em princípios ultrapassados de engenharia, onde a eficiência das intervenções consistia em drenar no menor tempo os volumes de água em direção à jusante (TUCCI, 2010).

Diante da ineficiência dos projetos ou da falta de manutenção, estas intervenções realizadas nos canais fluviais podem comprometer o fluxo natural das águas com o estrangulamento das seções transversais por lixos, sedimentos e demais materiais arrastado pelas águas para a calha fluvial.

Nesse contexto, foi realizada a análise das inundações na bacia do rio Mataruna. A partir do entendimento dos aspectos naturais, das intervenções realizadas no canal principal e seus afluentes, das mudanças no e cobertura da terra, buscou-se o entendimento dos fatores envolvidos nas inundações. Verificou-se que aumentaram as perdas materiais e os transtornos causados pelas inundações. No período entre 2000 e 2016, ocorreram várias inundações, segundo dados da Defesa Civil do município e amplamente noticiados. Duas inundações de grande proporção, ocorridas em abril de 2010 e fevereiro de 2016, provocaram grandes danos à população.

Em 05 de abril de 2010, foi registrado um volume de 122 milímetros em quatros horas, que provocou grandes transtornos na cidade e mais de 100 pessoas desabrigadas (Jornal O Globo -o6/04/2010, p. 14).

No dia 29 de fevereiro de 2016, choveu cerca de 148 milímetros em seis horas, segundo a Defesa Civil, o que provocou grandes prejuízos aos moradores e comerciantes deixando mais de 2.500 pessoas desalojadas, segundo a Defesa Civil (Rede InterTV, 02/03/2016). Com as inundações, foram interditados o Hospital Regional, a Delegacia de Polícia (Figura 3), o Pronto Socorro Municipal, além de outras repartições públicas.

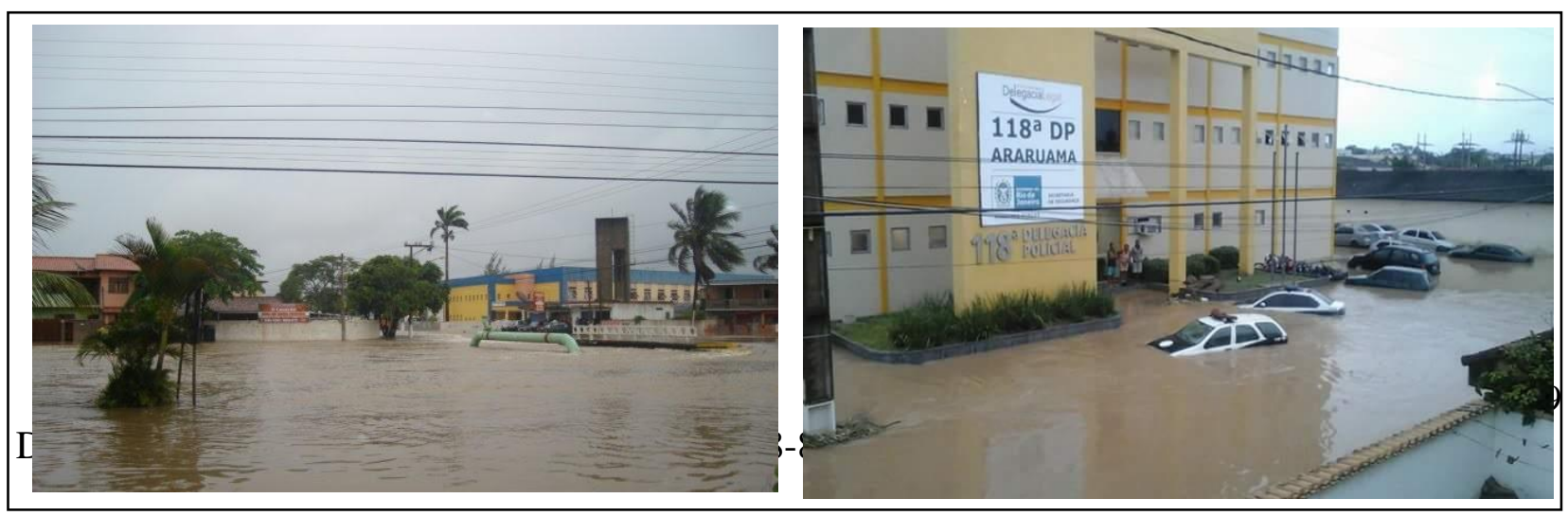


Figura 3 - Vista das áreas atingidas pelas chuvas de 29/02/2016. A esquerda, o Hospital Regional e a direita o prédio da Delegacia de polícia. (Fonte: Reprodução de www.g1.com.br)

Embora registre um histórico de inundações, as chuvas não são frequentes na bacia hidrográfica do rio Mataruna devido a diferentes fatores atuantes no clima. Segundo Barbieri (1975), esta área configura-se como uma "mancha seca" no úmido litoral fluminense. Os períodos espaçados de recorrência das inundações reduzem as medidas de prevenção em relação aos riscos que a população está exposta e contribui para as ocupações desordenadas em áreas de inundação natural do rio Mataruna e seus afluentes.

A pluviosidade anual média registrada é de 900 milímetros, bem abaixo dos volumes registrados nas demais regiões do litoral do Estado do Rio de Janeiro. Além do regime de chuvas, outro fator determinante na dinâmica das inundações está relacionado à topografia do terreno. As áreas de maior ocupação urbana possuem declividades inferiores a $2 \%$, o que contribui ainda para os alagamentos.

As inundações da bacia do rio Mataruna tem ainda como agravantes o quadro de degradação ambiental dos canais fluviais na área urbana. O acúmulo de lixo e entulho nas margens, os volumes expressivos de esgoto in natura lançados diretamente no canal e a proliferação de plantas aquáticas no leito dos canais principais reduzem a vazão durante as chuvas de maior intensidade e concentração. A falta de ordenação no uso do solo impede a realização de medidas preventivas, contribui para que a população esteja susceptível às perdas materiais, além do risco de doenças de veiculação hídrica, comuns após estes desastres naturais.

\section{Conclusão}

O uso de imagens de satélite (Ikonos, 2002 e 2016), através de técnicas de sensoriamento remoto, foi de grande importância na quantificação das classes de uso e cobertura da terra na bacia do rio Mataruna. Constatou-se que ocorreu o crescimento das ocupações desordenadas ao longo das margens dos canais principais, reduzindo a permeabilidade e aumentando o fluxo superficial durante as chuvas.

Os dados da Figura 2 e da Tabela II, mostram que as áreas urbanas apresentaram um crescimento sobre áreas de pastagens com o surgimento de novos condomínios residenciais. A imagem de 2016 mostra que houve uma alteração espacial das áreas ocupadas por vegetação secundária. Houve a redução destas formações vegetais próximo à área urbana e crescimento junto as áreas de pastagens, o que indica uma pequena regeneração da vegetação nas áreas rurais. As áreas de florestas apresentaram o maior 
crescimento segundo a Tabela II, passando de 2,4\% para 4,6\%, Entretanto, observa-se que estas formações vegetais apresentaram alterações em relação a distribuição espacial, com expansão em algumas áreas e redução em outras em decorrência da urbanização. Portanto, o presente trabalho atingiu seus objetivos ao identificar as alterações ocorridas no uso e cobertura da terra a partir da interpretação das imagens (Ikonos, 2002 e 2016) e suas influências nas inundações da bacia do rio Mataruna em Araruama/RJ.

\section{Bibliografia}

BARBIERE, E. B. - "Ritmo Climático e Extração de Sal em Cabo Frio" - São Paulo, Dissertação de Mestrado, USP, Departamento de Geografia, 1974. Publicado na Revista Brasileira de Geografia, 1975.

CANHOLI, Aluísio P. Drenagem urbana e controle de enchentes. São Paulo: Oficina de textos, 2005.

IBGE. Resultados do Universo. Censo Demográfico 2010. Rio de Janeiro. 2011.

GALVÃO, R. S. Gestão de bacias hidrográficas em áreas urbanas: Niteroi (RJ). Tese (Doutorado em Ordenamento Territorial Ambiental). Universidade Federal Fluminense, Niterói. 2014.

PREFEITURA MUNICIPAL DE ARARUAMA. Plano Diretor de Araruama. Lei No 008/95. 42p. 1997.

PREFEITURA MUNICIPAL DE ARARUAMA (2016) Plano Municipal de Saneamento Básico de Araruama. Serenco Em Engenharia/INEA. (versão preliminar) 142 p. 2016.

PESQUISA DA PECUÁRIA MUNICIPAL. Disponível em http://www2.sidra.ibge.gov.br.

SILVA, J.R.S. Estudo do Levantamento Aerogeofísico do Estado do Rio de Janeiro na Região dos Lagos. Tese de Doutorado. Observatório Nacional, Rio de Janeiro. 2007.

TUCCI, E.M. Água no meio urbano. In: Águas doces do Brasil. p.399-431. 2010.

VIEIRA, V. T. Efeitos do crescimento urbano sobre os canais: drenagem do rio Paquequer, Teresópolis - RJ. Rio de Janeiro: UFRJ/ PPGG - Dissertação de Mestrado. 101 p.2003.

REDE INTERTV. http://g1.globo.com/rj/regiao-dos-lagos/rjintertv-2edicao/videos/t/edicoes/v/defesa-civil-ficaem-estado-de-atencao-apos-chuva-deixar-2-500-desalojados-em-araruama/4855345/. 